\title{
The Effect of Type 1 Diabetes Mellitus on the Craniofacial Complex
}

\author{
Mona Abbassy ${ }^{1,2,3}$, Ippei Watari ${ }^{1}$ and Takashi Ono ${ }^{1}$ \\ ${ }^{1}$ Orthodontic Science, Department of Orofacial Development and Function, \\ Division of Oral Health Sciences, Tokyo Medical and Dental University, \\ ${ }_{2}^{2}$ reventive Dental Sciences Department, Orthodontic Department Devision, \\ King AbdulAziz University, \\ ${ }^{3}$ Alexandria University \\ IJapan \\ ${ }^{2}$ Saudia Arabia \\ ${ }^{3}$ Egypt
}

\section{Introduction}

Diabetes mellitus (DM) is one of the systemic diseases affecting a considerable number of patients (Bensch et al., 2003). Numerous experimental and clinical studies on the complications of diabetes mellitus have demonstrated extensive alterations in bone and mineral metabolism, linear growth, and body composition (Giglio and Lama, 2001). DM is a metabolic disorder characterized by disturbed glucose metabolism, manifesting primarily as chronic hyperglycemia.

Bone metabolism is impaired in Type 1 Diabetes Mellitus (T1DM), either through the direct effect of insulin deficiency or hyperglycaemia or via the more long-term effects of vascular disease. Previous data suggested that osteoblast function can be corrected by restoration of glycaemic control, indicating that hyperglycaemia produces direct impairment of bone metabolism (Shyng et al., 2001).

Growth is a highly complex mechanism resulting not only in a major change in size, but also in minor changes in shape. The changes in shape of the craniofacial skeleton are of particular interest because pathological growth of certain anatomical regions may lead to functional and esthetic problems. In the craniofacial skeleton, it has been well known that growth involves a mosaic of growth sites that grow at different rates and mature at different times (Vandeberg et al., 2004a; VandeBerg et al., 2004b), its growth and by analogy, the response to growth disruption is much more complex than that of the appendicular skeleton (Vandeberg et al., 2004a). Different parts of the craniofacial complex might be expected to respond differently to the same hormonal or biomechanical stimulus (VandeBerg et al., 2004b). T1DM has been shown to affect the general growth of patients due to insulin deficiency and consequently leads to delayed skeletal maturation (Schwartz, 2003).

\section{Types of bone formation in craniofacial complex}

Bone forms in two ways, resulting in two types of mature bone - intramembranous and cartilage. Cartilage bone forms in a replacement process within the cartilage models of the 
embryo and infant. Intramembranous bone forms through the activation of the osteoblast cell or specialized bone forming cells in one of the layers of fetal connective tissue. The bones of the cranial vault, the face, and the clavicle are intramembranous in origin. All other bones of the body form from cartilage. Intramembranous bone include the mandible, the maxilla, the premaxilla, the frontal bone, the palatine bone, the squamous part of temporal bone, the zygomatic bone, the medial plate of the pterygoid process, the vomer, the tympanic part of the temporal bone, the nasal bone, the lacrimal bone, and the parietal bone. The original pattern of intramembranous bone changes with progressive maturative growth when these bones begin to adapt to environmental influences. This accounts for deformities due to malfunction, disease and other environmental factors (Salzmann, 1979).

\section{Causes of growth problems}

Growth disturbances can be associated with specific anatomic or functional defects. They may be of endocrine or non endocrine origin and may result from genetic, nutritional or environmental factors. Disturbances in somatic growth show themselves in retardation or acceleration of the skeletal system, including the facial and cranial bones. Causes for growth problems usually fall into the following categories (Kumar, 2009):

- Familial short stature

Familial short stature is a tendency to follow the family's inherited short stature (shortness).

- Constitutional growth delay with delayed adolescence or delayed maturation

A child who tends to be shorter than average and who enters puberty later than average, but is growing at a normal rate. Most of these children tend to eventually grow to approximately the same height as their parents.

- Illnesses that affect the whole body (Also called systemic diseases)

Constant malnutrition, digestive tract diseases, kidney disease, heart disease, lung disease, hepatic disease, diabetes, and severe stress can cause growth problems.

- Endocrine (hormone) diseases

Adequate production of the thyroid hormone is necessary for normal bone growth. Cushing's syndrome can be caused by a myriad of abnormalities that are the result of hypersecretion of corticosteroids by the adrenal gland. Growth hormone deficiency involves a problem with the pituitary gland (small gland at the base of the brain) that secretes several hormones, including growth hormone.

- Congenital (present at birth) problems in the tissues where growth occurs

A condition called intrauterine growth restriction (IUGR), slow growth within the uterus occurs during a pregnancy. The baby is born smaller in weight and length than normal, in proportion to his/her short stature.

\section{Outline of studying the effect of diabetes mellitus on craniofacial growth}

Approximately $60 \%$ of adult bone mass including craniofacial bone is gained during the peak of the growth period which coincides with the onset of T1DM condition affecting the bone formation process (Eastell and Lambert, 2002). It is worth mentioning here that although T1DM condition exact etiological factors are totally unknown however; understanding the course of T1DM condition and its impact on craniofacial development may lead to improving the oral health for a large sector of the population worldwide. 
Numerous experimental and clinical studies on the complications of DM have demonstrated extensive alterations in bone and mineral metabolism, linear growth, and body composition. Investigators in the fields of bone biology including orthodontics have long been interested in the general causes that affect the normal growth of the craniofacial region. T1DM has been shown to affect the general growth of patients with earlier onset of the disease, especially onset before or around the circumpubertal growth spurts (Chew, 1991).

In general, growth of the craniofacial complex is controlled by genetic and environmental factors (Giglio and Lama, 2001; Yonemitsu et al., 2007). Regulatory mechanisms responsible for normal morphogenesis of the face and head involve hormones, nutrients, mechanical forces, and various local growth factors. The poor growth and alterations in bone metabolism have been associated with T1DM in both humans and experimental animals (Giglio and Lama, 2001). It is of prime importance investigating the changes in craniofacial bone structure and dynamic bone formation in DM condition to explore the impact of the diabetic condition on various mandibular growth elements and bone quality.

The following parts of this chapter are going to focus on these points:

- Investigating the effects of juvenile diabetes on general craniofacial growth and skeletal maturation.

- Analyzing the pattern of association between craniofacial morphology and skeletal maturation.

- Determination of the changes in bone morphology in diabetic rat mandible using microC.T.

- Determination of the mineral apposition rate and the bone formation rate in diabetic rat mandible using histomorphometric analysis.

\section{Animal and experimental diabetic model}

The animal studies using diabetic model presents various advantages when compared to studies carried out on human diabetic cases. Human studies can be limited by small sample sizes, cross-sectional designs, uncontrolled variables, and often retrospective nature, animal models have been used to yield more rigorous analyses (Singleton et al., 2006).

\subsection{Diabetic model}

Experimental diabetic models include the streptozotocin-induced diabetic rat and the spontaneously diabetic BioBreeding rat. The occurrence of different abnormalities indicating altered bone formation after inducing DM with streptozotocin (STZ) is well documented (Giglio and Lama, 2001; Hough et al., 1981; Tein et al., 1998). Streptozotocin-induced diabetes mellitus (STZ-DM), caused by the destruction of pancreatic $\beta$-cells and is similar to T1DM in human, is characterized by mild to moderate hyperglycemia, glucosuria, polyphagia, hypoinsulinemia, hyperlipidemia, and weight loss. STZ-DM also exhibits many of the complications observed in human DM including enhanced susceptibility to infection and cardiovascular disease, retinopathy, alterations in angiogenesis, delayed wound healing, diminished growth factor expression, and reduced bone formation (Lu et al., 2003).

\subsection{Importance of testing the uncontrolled diabetic condition}

In the usual clinical situation, although T1DM patient is treated with insulin, patient may still suffer from an overall poor diabetic metabolic state with an uncontrollable blood glucose level and a high and sometimes changing insulin requirement (Follak et al., 2004). 


\subsection{Inducing diabetic condition}

All the experimental protocols followed had been approved by the Institutional Animal Care and Use Committee of Tokyo Medical and Dental University, and the experiments were carried out under the control of the University's Guidelines for Animal Experimentation. In our investigation we explored the various effects of DM using the streptozotocin DM model. Twelve 3-week old male Wistar rats were used for this study. They were randomly divided into two groups, the control group and the diabetes group (DM group), each group consists of 6 rats. The rats in the control group were injected intraperitoneal with a single dose of $0.1 \mathrm{M}$ sodium citrate buffer $(\mathrm{pH} 4.5)$, while the rats in the DM group were injected intra-peritoneal with a single dose of citrate buffer containing $60 \mathrm{mg} / \mathrm{kg}$ body weight of streptozotocin (Sigma Chemical Co., St. Louis, MO, USA).(Alkan et al., 2002; McCracken et al., 2006; Shyng et al., 2001; Tein et al., 1998) All animals were fed on standard Rodent diet (Rodent Diet CE-2; Japan Clea Inc., Shizuoka, Japan) with free access to water. Body weights, the presence of glucose in urine and blood glucose levels were recorded on day $0,2,7,14,21$ and 28 after STZ injection.

Diabetes condition was determined by the presence of glucose in urine and blood. The urine of the rats was tested using reagent strips (Uriace Ga; TERUMO). (Abdus Salam et al., 2004; Matin et al., 2002) Blood samples of the rats were obtained via vein puncture of a tail vein, and blood glucose levels were determined using a glucometer (Ascensia Brio. Bayer Medical). Positive urine test and a blood glucose level greater than $200 \mathrm{mg} / \mathrm{dl}$ was considered DM.(Giglio and Lama, 2001).

Fig. 1. shows the weights of the rats $($ mean $\pm S D)$ in both groups. DM group showed a significant decrease in weight. After STZ injection by 48 hours the urine test showed that the entire DM group had a high glucose level and this was confirmed by the high blood glucose measurements as shown in Fig. 2. A Student's t-test was used to compare the mean of weights and blood glucose levels in both groups.

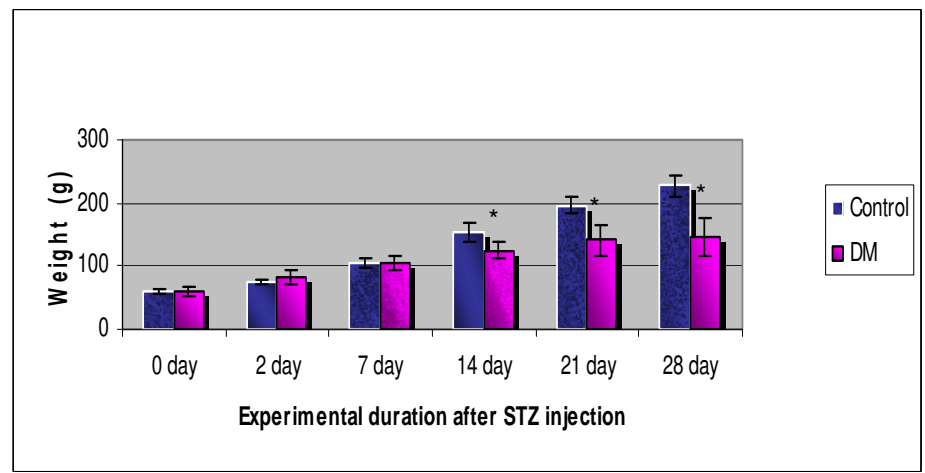

Fig. 1. Comparison between the changes of the rat's weight in the control and DM group. The weights of the DM group are significantly decreased as compared to the weights of the control group $\left(^{*}: p<0.05\right)$. 


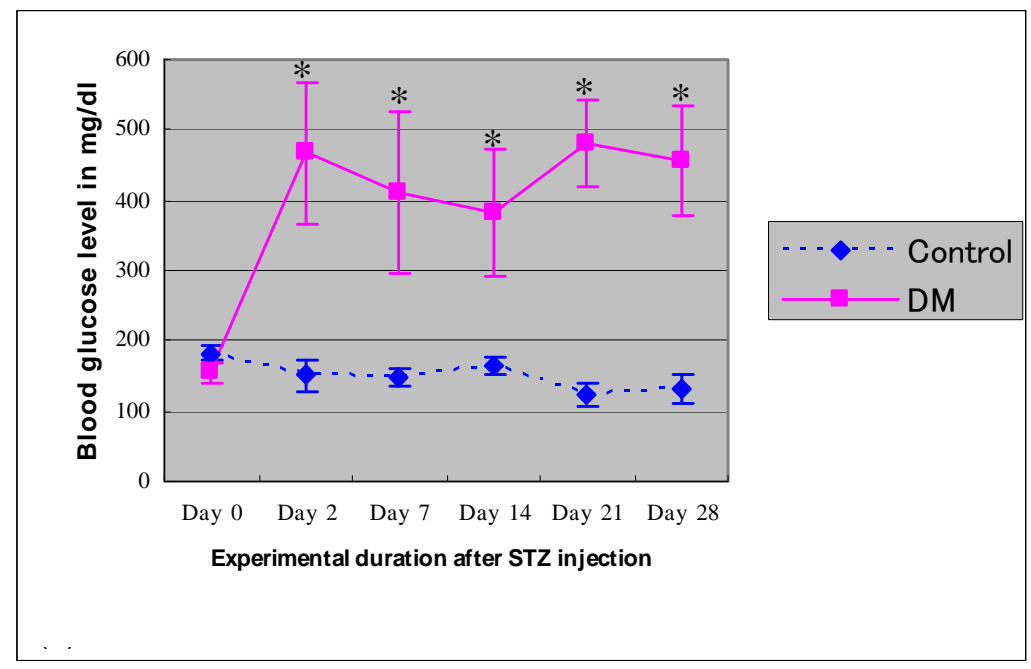

Fig. 2. Line graph represents the blood glucose levels for the control and DM group. The blood glucose level in DM group increased significantly $48 \mathrm{~h}$ post-STZ injection and during the entire experimental period. Values are mean $\pm S D$. Significant differences between the two groups are marked with asterisks $(p<0.05)$.

\section{Analytic studies conducted to test the effect of diabetic condition on craniofacial growth}

\subsection{Cephalometric analysis}

Cephalometric measurements are still one of the most widely spread diagnostic aids crucial for the diagnosis of various abnormalities in the craniofacial complex (Chidiac et al., 2002).

The protocol for examining the cephalometric measurements in DM rats involves the following steps:

- Prior to each radiographic session, the rats are anaesthetized with diethyl ether and intraperitoneal injection of $8 \%$ chloral hydrate using $0.5 \mathrm{ml} / 100 \mathrm{~g}$ of body weight.

- Each animal is then placed in this specially-designed apparatus (Fig. 3) to maintain standardized head posture and contact with the film (SGP-3, Mitsutoy, Tokyo, Japan) where the head of each rat is fixed firmly with a pair of ear rods oriented vertically to the sagittal plane and the incisors are fixed into a plastic ring.

- The settings of lateral and dorsoventral cephalometric radiographs are $50 / 55 \mathrm{kVp}$, 15/10mA, and 20/60-sec impulses respectively (Singleton et al., 2006; Vandeberg et al., 2004a; VandeBerg et al., 2004b).

- A $10 \mathrm{~mm}$ steel calibration rod is incorporated into the clear acrylic table on which the animals are positioned for the radiographs.

- All the radiographs are developed and scanned at high resolution by the same operator (Singleton et al., 2006).

The cephalometric landmarks (Table 1; Fig. 4) were derived from previous studies on rodents (Engstrom et al., 1988; Kiliaridis and Thilander, 1985; Singleton et al., 2006; Vandeberg et al., 2004a; VandeBerg et al., 2004b). Selected linear measurements were then 
obtained (Table 2). To ensure reliability and replicability of each measurement, each distance was digitized twice and the two values were averaged.

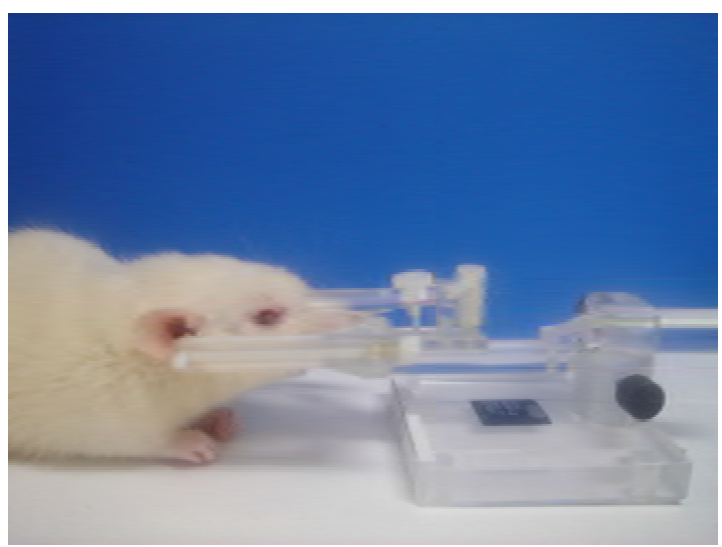

Fig. 3. Apparatus for roentgenographic cephalometry
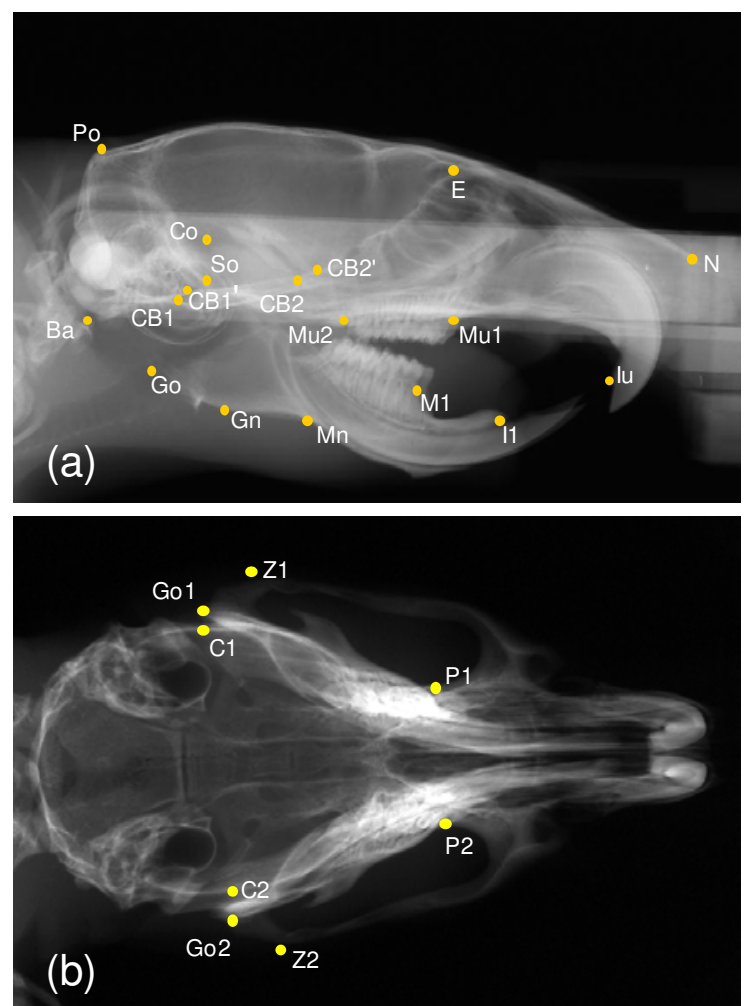

Fig. 4. Location of cephalometric points on radiographs: (A) Sagittal and (B) transverse. 


\section{On the sagittal radiograph}

$\mathrm{N}$ : The most anterior point on the nasal bone

E: The intersection of the frontal bone and floor of anterior cranial fossa

Po: The most posterior and superior point on the skull

Ba: The most posterior and inferior point on the occipital condyle

Co: The most posterior and superior point on the mandibular condyle

Go: The most posterior point on the mandibular ramus

$\mathrm{Mn}$ : The most concave portion of the concavity on the inferior border of the mandibular corpus

Gn: The most inferior point on the ramus that lies on a perpendicular bisector of the line Go-Mn

Il: The most anterior and superior point on the alveolar bone of the mandibular incisor

So: The intersection of the most anterior tympanic bulla and the superior border of the sphenoid bone

CB1: The most anterior point on the occipital bone at the spheno-occipital synchondrosis

CB1 $1^{\prime}$ : The most posterior point on the sphenoid bone at the spheno-occipital synchondrosis

CB2: The most anterior point on the sphenoid bone at the spheno-basispheno synchondrosis

$\mathrm{CB} 2^{\prime}$ : The most posterior point on the basisphenoid bone at the spheno-basispheno-synchondrosis

Ml: The junction of the alveolar bone and the mesial surface of the first mandibular molar

Mu1: The junction of the alveolar bone and the mesial surface of the first maxillary molar

Mu2: The junction of the alveolar bone and the distal surface of the third maxillary molar

Iu: The most anterior-inferior point on the maxilla posterior to the maxillary incisors

\section{On the transverse radiograph}

Z1 \& Z2: The points on the lateral portion of the zygomatic arch that produce the widest width

Go1 \& Go2: The points on the angle of the mandible that produce the widest width

P1 \& P2: The most anterior and medial points within the temporal fossae that produce the most narrow palatal width

C1 \& C2: The points on the cranium that produce the widest cranial width

Table 1. Definition of radiographic points 


\author{
Neurocranium \\ Po-N: total skull length \\ Po-E: cranial vault length \\ Ba-E: total cranial base length \\ So-E: anterior cranial base length \\ Ba-CB 1: occipital bone length \\ $\mathrm{CB}^{\prime}$-CB2: sphenoid bone length \\ Ba-So: posterior cranial base length \\ Po-Ba: posterior neurocranium height \\ Viscerocranium \\ E-N: nasal length \\ Mu2-Iu: palate length \\ CB2-Iu: midface length \\ E-Mu1: viscerocranial height

\section{Mandible} \\ Go-Mn: posterior corpus length \\ Ml-Il: anterior corpus length \\ Co-Il: total mandibular length \\ Co-Gn: ramus height \\ Transverse $X$-ray \\ Go1-Go2: Bigonial width \\ C1-C2: Maximum cranial width \\ P1-P2: Palatal width \\ Z1-Z2: Bizygomatic width
}

Table 2. Measurements of craniofacial skeleton

In our studies, evaluation of the craniofacial growth of diabetic rats at the age of 7 weeks was done using lateral and dorsoventral cephalometric radiographs. All of the data in each experiment were confirmed the normal distribution, so a Student's t-test was used to compare the mean of each data recorded in the control group and in the DM group. All statistical analyses were performed at a 5\% significance level using statistic software (v. 10; SPSS, Chicago, IL, USA).

\title{
6.1.1 Changes in the total skull
}

The size of total skull, denoted by Po-N, was significantly smaller in the DM group than in the control group.

\subsubsection{Changes in the neurocranium}

Cranial vault length (Po-E), total cranial base length (Ba-E), anterior cranial base length (SoE), Occipital bone length (Ba-CB1), and posterior cranial base length (Ba-So) showed statistically significant decrease in DM group (Table 3, Figs. 5, 6), while other dimensions exhibited no significant differences. 


\begin{tabular}{ll}
\hline Po-N & total skull length \\
\hline Po-E & cranial vault length \\
\hline Ba-E & total cranial base length \\
\hline So-E & anterior cranial base length \\
\hline Ba-CB1 & occipital bone length \\
\hline Ba-So & posterior cranial base length \\
\hline
\end{tabular}

Table 3. Significant changes in the total skull and neurocranium

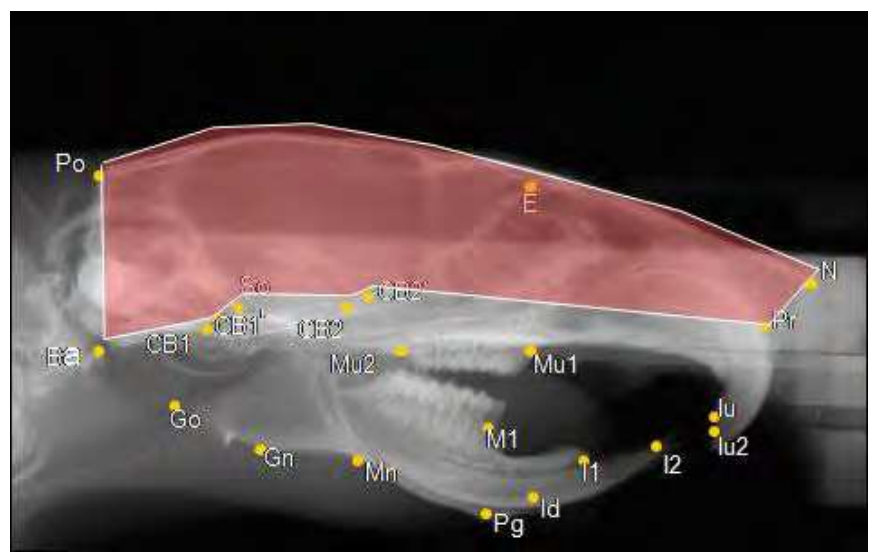

Fig. 5. Neurocranium

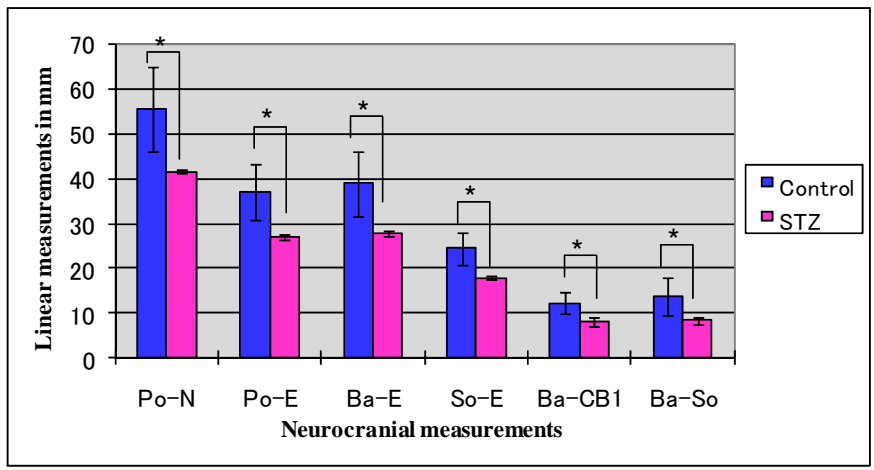

Fig. 6. Changes in the neurocranial measurements of the control and DM group. All the significant measurements are shown in this figure. Values are mean \pm S.D. Significant differences between the two groups are marked with asterisks $(p<0.05)$.

\subsubsection{Changes in the viscerocranium}

All measurements of the viscerocranium, including the nasal length $(\mathrm{E}-\mathrm{N})$, palatal length (Mu2-Iu), midface length (CB2-Iu), and viscerocranial height (E-Mu1) showed a statistically significant decrease in DM group (Table 4, Figs. 7,8) 


\begin{tabular}{ll}
\hline E-N & Nasal length \\
Mu2-Iu & Palate length \\
Cb2-Iu & midface length \\
E-Mu1 & Posterior viscerocranial height \\
\hline
\end{tabular}

Table 4. Significant changes in the viscerocranium

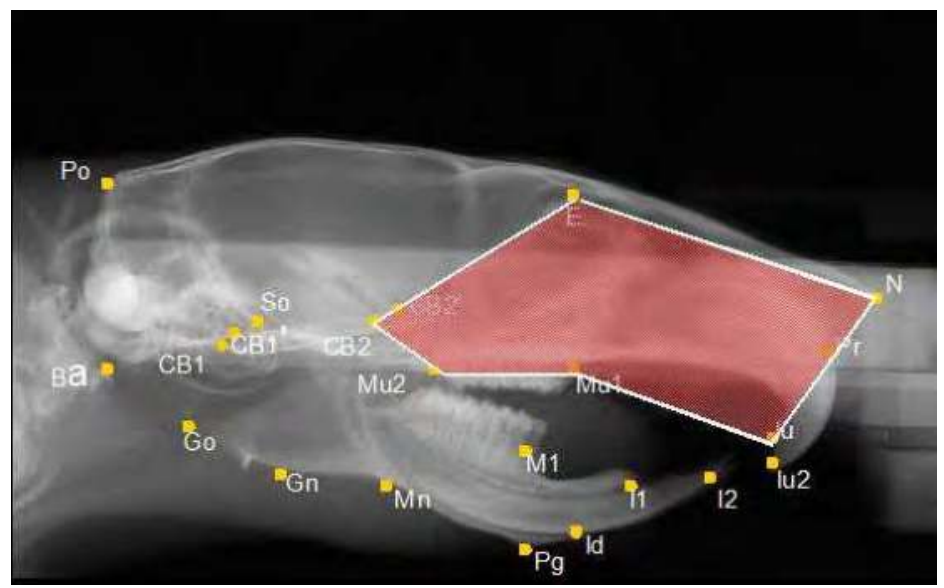

Fig. 7. Viscerocranium

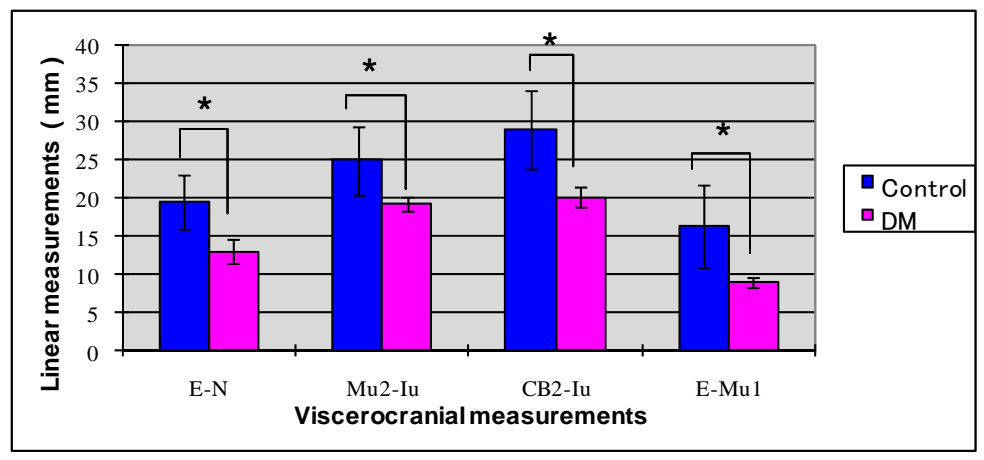

Fig. 8. Changes in the viscerocranial measurements of the control and DM group. All the viscerocranial measurements are significant. Values are mean \pm S.D. Significant differences between the two groups are marked with asterisks $(p<0.05)$.

\subsubsection{Changes in the mandible}

In the DM group, the posterior corpus length (Go-Mn), total mandibular length (Co-Il) and the ramus height (Co-Gn) were significantly shorter than in the control group (Table 5, Figs. $9,10)$, whereas no remarkable differences were found in the remaining dimensions. 


\begin{tabular}{ll}
\hline Go-Mn & Posterior corpus length \\
Co-Il & Total mandibular length \\
\hline Co-Gn & Ramus height \\
\hline
\end{tabular}

Table 5. Significant changes in the mandible

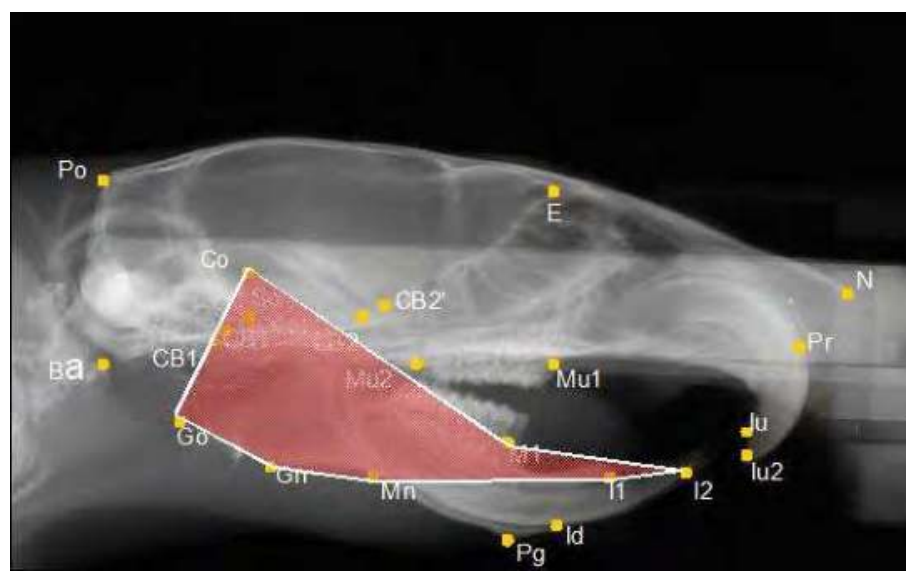

Fig. 9. Mandible

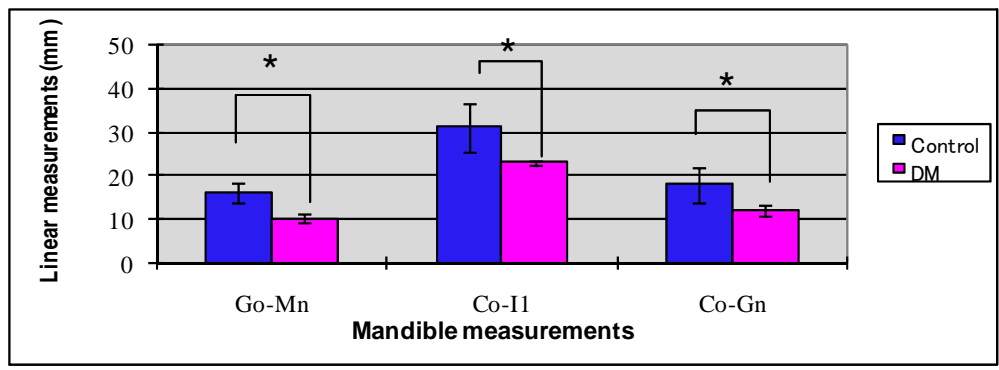

Fig. 10. Changes in the mandible measurements of the control and DM group. Values are mean \pm S.D. Significant differences between the two groups are marked with asterisks $(p<0.05)$.

\subsubsection{Changes in the transverse X-ray}

In transverse $X$-ray only the maximum cranial width (C1-C2) and the bizygomatic width (Z1-Z2) were statistically decreased in DM group (Table 6, Figs. 11, 12).

All other linear measurements showed no significant differences between both groups

\begin{tabular}{ll}
\hline C1-C2 & Maximum cranial width \\
Z1-Z2 & Bizygomatic width \\
\hline
\end{tabular}

Table 6. Significant changes in the transverse X-ray 


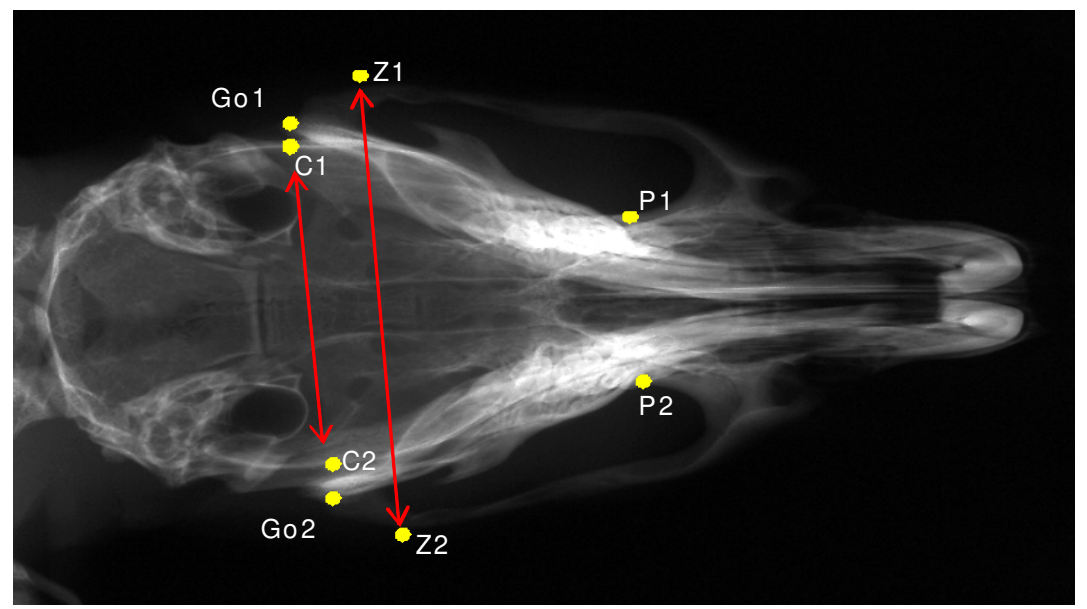

Fig. 11. Transverse $\mathrm{X}$-ray measurements

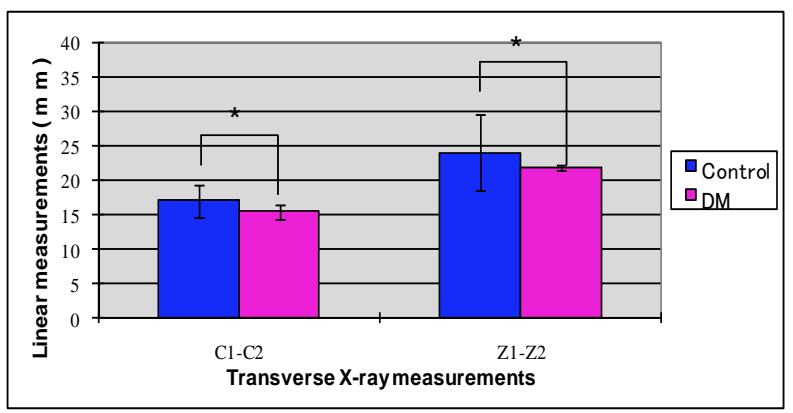

Fig. 12. Changes in the transverse $X$-ray measurements of the control and DM group. Two measurements in the transverse $X$-ray were significant. Values are mean $\pm S$.D. Significant differences between the two groups are marked with asterisks $(p<0.05)$. 


\begin{tabular}{|c|c|c|c|c|}
\hline \multirow[b]{2}{*}{ Linear measurements } & \multicolumn{2}{|c|}{$D M$} & \multicolumn{2}{|c|}{$C$} \\
\hline & Mean & SD & Mean & SD \\
\hline \multicolumn{5}{|l|}{ Neurocranium } \\
\hline Po-N & 41.67 & $0.59 *$ & 55.61 & 9.48 \\
\hline Po-E & 26.86 & $0.6^{*}$ & 37.12 & 6.35 \\
\hline Ba-E & 27.74 & $0.64 *$ & 38.87 & 7.19 \\
\hline So-E & 17.91 & $0.31 *$ & 24.41 & 3.72 \\
\hline $\mathrm{Ba}-\mathrm{CB} 1$ & 8.23 & $1.08^{*}$ & 12.3 & 2.34 \\
\hline $\mathrm{CB} 1^{\prime}-\mathrm{CB} 2$ & 4.78 & 0.74 & 5.93 & 1.18 \\
\hline Ba-So & 8.44 & $0.7 *$ & 13.61 & 4.23 \\
\hline Po-Ba & 10.03 & 0.83 & 13.14 & 2.81 \\
\hline \multicolumn{5}{|l|}{ Viscerocranium } \\
\hline E-N & 13.07 & $1.56^{*}$ & 19.57 & 3.48 \\
\hline Mu2-Iu & 19.34 & $0.95^{*}$ & 25.01 & 4.5 \\
\hline CB2-Iu & 20.16 & $1.29 *$ & 29 & 5.07 \\
\hline E-Mu1 & 8.93 & $0.69^{*}$ & 16.43 & 5.36 \\
\hline \multicolumn{5}{|l|}{ Mandible } \\
\hline Go-Mn & 10.27 & $1.04^{*}$ & 16 & 2.39 \\
\hline M1-I1 & 5.4 & 0.88 & 6.97 & 1.54 \\
\hline Co-I1 & 22.95 & $0.34 *$ & 31.13 & 5.51 \\
\hline Co-Gn & 12.22 & $1.2^{*}$ & 17.9 & 4.04 \\
\hline \multicolumn{5}{|l|}{ Transverse $X$-ray } \\
\hline Go1-Go2 & 18.42 & 0.42 & 19.77 & 1.32 \\
\hline $\mathrm{C} 1-\mathrm{C} 2$ & 15.43 & $0.67^{*}$ & 17.03 & 1.16 \\
\hline P1-P2 & 8.5 & 0.41 & 9.19 & 0.52 \\
\hline Z1-Z2 & 21.9 & $0.33^{*}$ & 24 & 1.4 \\
\hline
\end{tabular}

${ }^{*} p<0.05$ as compared to control values

Table 7. Comparision of skeletal cephalometric measurements for Type 1 Diabetes mellitus (DM) and controls (C)

\subsection{Histomorphometric analysis}

\subsubsection{Fluorescent dyes used for double labeling in histomorphometric analysis}

Fluorochromes are calcium binding substances that are preferentially taken up at the site of active mineralization of bone known as the calcification front, thus labeling sites of new bone formation. They are detected using fluorescent microscopy on undecalcified sections. Labeling bones with fluorochrome markers provides a means to study the dynamics of bone formation. The rate and extent of bone deposition and resorption can be determined using double and triple fluorochrome labeling sequences. The sequential use of fluorochromes of clearly contrasting colors permits a more detailed record of events relating to calcification. Flurochromes commonly used in mammals include tetracycline, calcein green, xylenol orange, alirazin red, and hematoporphyrin. Calcein is a fluoresces bright green when combined with calcium (Stuart and Smith, 1992). 


\subsubsection{Calcein administrations and sections preparation}

The steps needed for detecting the double labeling involves the following:

- Rats are subcutaneously injected with $50 \mathrm{mg} / \mathrm{kg}$ body weight calcein fluorescent marker on day 21 and day 28 after STZ injection. The time difference between the 2 injections is one week to be able to compare the amount of bone formed during this period (Fig. 14).

- Sacrifice of all animals by transcardiac perfusion under deep anesthesia using $4 \%$ paraformaldehyde in $0.1 \mathrm{M}$ phosphate buffer ( $\mathrm{pH}$ 7.4).

- Mandibles are dissected and fixed in the same solution for 24 hours.

- All specimens are embedded in polystyrene resin (Rigolac, Nisshin EM Co. Ltd., Tokyo, Japan).

- Undemineralized ground frontal sections are processed to show the crown and both apices of buccal and lingual roots of the lower second molar (Shimomoto et al., 2007).

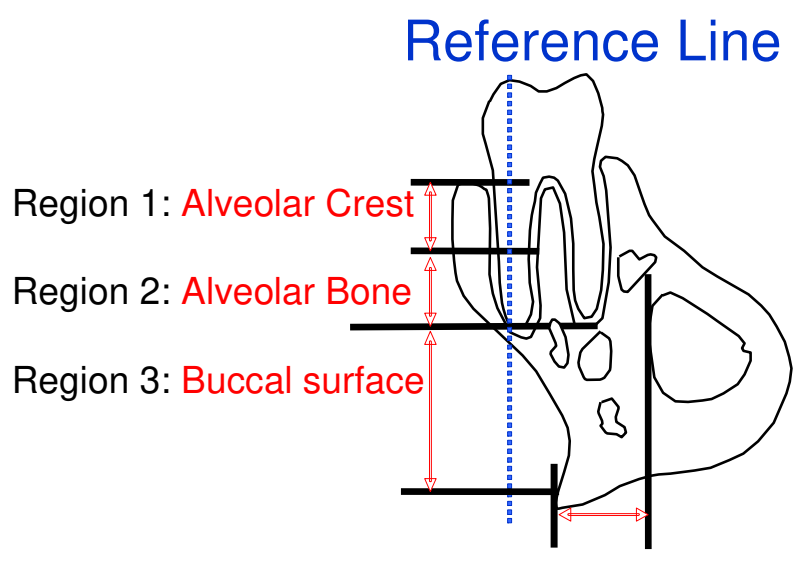

Region 4: Inferior Border

Fig. 13. Schematic drawing of observation regions for dynamic bone histomorphometry. The periosteal surfaces were delimited into 4 areas as alveolar crest (region 1), alveolar bone (region 2), buccal surface of the jaw bone (region 3), and inferior border of the jaw bone (region 4).

\subsubsection{Method of analysis}

The bone around the lower second molar is centrally located within the mandibular arch, and because of the parallel alignment of the buccal and lingual roots this made a precise reference when frontal sections are produced (Shimomoto et al., 2005). To conduct the histomorphometric analysis it is essential to use a digitizing morphometry system to measure bone formation indices. The system consists of a confocal laser scanning microscope (LSM510, Carl Zeiss Co. Ltd., Jena, Germany), and a morphometry program (LSM Image Browser, Carl Zeiss Co. Ltd., Jena, Germany). Bone formation indices of the periosteal surfaces of the alveolar/jaw bone include mineral apposition rate $(\mu \mathrm{m} /$ day) and bone formation rate $\left(\mu \mathrm{m}^{3} / \mu \mathrm{m}^{2} /\right.$ day), according to the standard nomenclature described by (Parfitt et al., 1987). The calcein-labeled surface (CLS, in $\mathrm{mm}$ ) is calculated as the sum of the length of double labels (dL) plus one half of the length of single labels (sL) along the entire endosteal or periosteal 
bone surfaces; that is, CLS $=\mathrm{dL}+0.5 \mathrm{sL}$ (Keshawarz and Recker, 1986). The mineral apposition rate (MAR, in $\mu$ /day) is determined by dividing the mean of the width of the double labels by the interlabel time (7 days). The bone formation rate (BFR) is calculated by multiplying MAR by CLS (Sheng et al., 1999). Based on the reference line along the long axis of the buccal root, the area superior to the root apex was considered alveolar bone, while the area inferior to the root apex was considered the jaw bone. The lingual side of the bone is excluded, because the existence of the incisor root may influence bone formation.

The periosteal surfaces of the mandible are divided into four regions for analysis (Fig. 13):

Region 1: alveolar crest (upper 1/2 of the tooth root, near the tooth crown)

Region 2: alveolar bone (lower $1 / 2$ of the tooth root, near the root apex)

Region 3: buccal surface of the jaw bone

Region 4: inferior border of the jaw bone

\subsubsection{Histomorphometric indices}

The obtained results in our study showed that in the alveolar bone (region 2), there was a significant decrease in the MAR (Fig. 15A) BFR (Fig. 15B) recorded in the DM group compared to the control group. However, in the alveolar crest (region 1), the MAR and the BFR in the control and the DM groups were not significantly different. $(p<0.05)$. In the buccal surface (region 3) and inferior borders (region 4) of the jaw bone the MAR (Fig. 15A) and BFR (Fig. 15B) were significantly suppressed compared with those in the control group $(p<0.05)$. Most of the periosteal surfaces in the mandibular regions of the control group showed significantly higher values recorded for the mineral apposition rate and the bone formation rate when compared to the DM group. These results agree with previous studies that recorded diminished lamellar bone formation in DM rats' femur and may suggest an association between the DM condition and the decreased number and function of osteoblasts (Follak et al., 2004; Shyng et al., 2001). The alveolar crest region was the only region that did not show a significant difference in the mineral apposition rate and the bone formation rate parameters among the two groups; this may be attributed to the unique nature of this region exhibiting a highly intensive bone remodeling process especially during the teeth eruption that decreases toward the base of the socket (Gerlach et al., 2002), however further studies are needed to elaborate the detailed pattern of bone growth at the alveolar crest region.
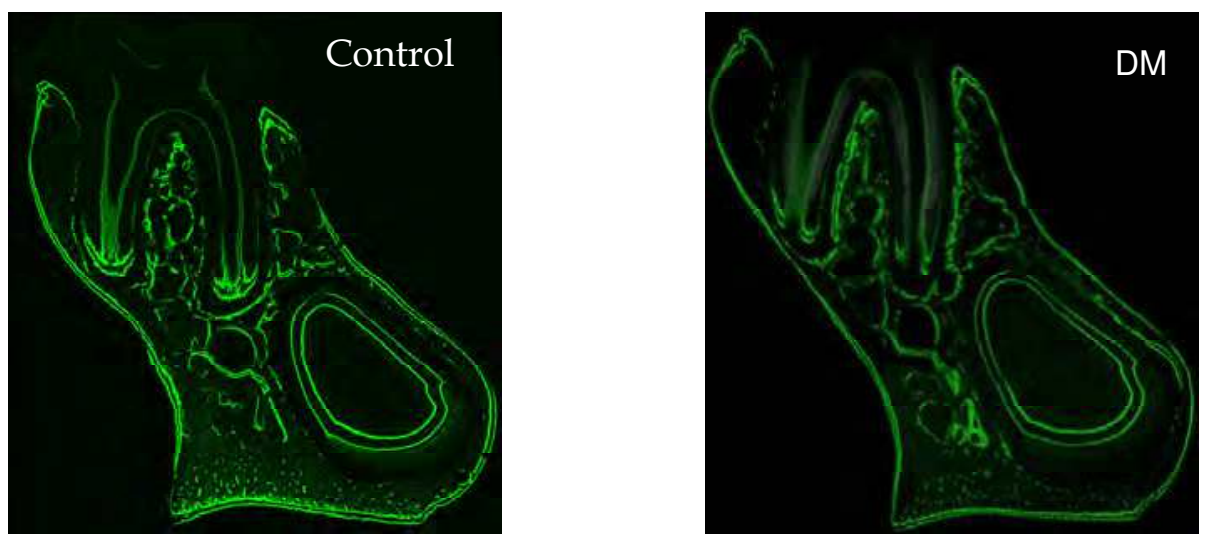

Fig. 14. Frontal sections of the mandibular second molar area. (A) Control; (B) DM. Fluorescent labeling on the periosteal surface indicates new bone formation. 


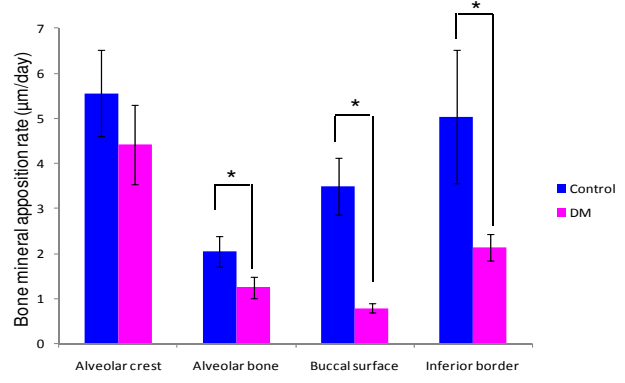

A

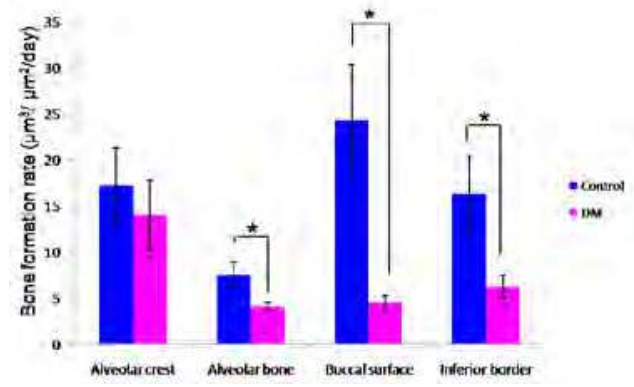

B

Fig. 15. (A) The changes in mineral apposition rate (MAR) of the mandible between the control group and the DM group. Alveolar crest (region 1, upper 1/2 of the tooth root, near the tooth crown). Alveolar bone (region 2, lower $1 / 2$ of the tooth root, near the root apex). Buccal surface of the jaw bone (region 3). Inferior border of the jaw bone (region 4). The data are expressed as means $\pm S D$. $n=5$ for each group. ${ }^{*}: p<0.05$. (B) The changes in the bone formation rate (BFR/BS) of the mandible between the control group and the DM group. Alveolar crest (region 1, upper 1/2 of the tooth root, near the tooth crown). Alveolar bone (region 2, lower $1 / 2$ of the tooth root, near the root apex). Buccal surface of the jaw bone (region 3). Inferior border of the jaw bone (region 4). The data are expressed as means \pm S.D. $\mathrm{n}=5$ for each group. *: $p<0.05$.

\subsection{Microtomography of the mandible (micro-CT)}

Micro-computed tomography (micro-CT) has rapidly become a standard technique for the visualization and quantification of the 3D structure of trabecular bone. Bone architecture and mineralization are generally considered to be important components of bone quality, and determine bone strength in conjunction with bone mineral density.

\subsubsection{Protocol adopted to examine the mandible using micro-CT}

In our study all specimens were imaged by micro-CT (inspeXio SMX-90CT; Shimadzu Science East Corporation, Tokyo, Japan)

- After removing only the soft tissue, the mandibular plane is set orthogonal to the sample stage.

- Three dimensional images of each hemi mandible are acquired with a resolution voxel size of $15 \mu \mathrm{m}$ / pixel.

- $\quad$ Raw data are obtained by rotating the sample stage 360 degrees. Then, slice images are prepared using multi-tomographic image reconstruction software (MultiBP; Imagescript, Tokyo, Japan).

- The resulting gray-scale images are segmented using a low-pass filter to remove noise and a fixed threshold to extract the mineralized bone phase.

- The volume of interest is drawn on a slice-based method starting from the first slice containing the crown of the first molar and moving dorsally 100 slices (Laib and Ruegsegger, 1999; Zhang et al., 2008), in the area of the alveolar crest (Between the buccal and lingual roots of the second molar at the cervical region); and the buccal surface of the jaw bone (Shimomoto et al., 2007). Trabecular bone was carefully contoured on the first and the last slice, while the intermediate slices were first interpolated by morphing. 
- For observation and analysis of reconstructed 3D images, 3D trabecular structure analysis software (TRI/3D-BON; RATOC System Engineering, Tokyo, Japan) is used (Takada et al., 2006). Reconstructed 3D images were prepared from slice images using the volume rendering method, to analyze the microstructure of the bone (Fig. 16).

- The following parameters are measured: tissue volume (TV), bone volume (BV), bone surface (BS), bone surface / bone volume (BS/BV), bone-volume fraction (BV/TV).

- Four properties of the trabeculae are evaluated: trabecular thickness (Tb.Th), trabecular number (Tb.N), trabecular separation (Tb.Sp), and Trabecular space (Tb.S) (Nakano et al., 2004; Takada et al., 2006).

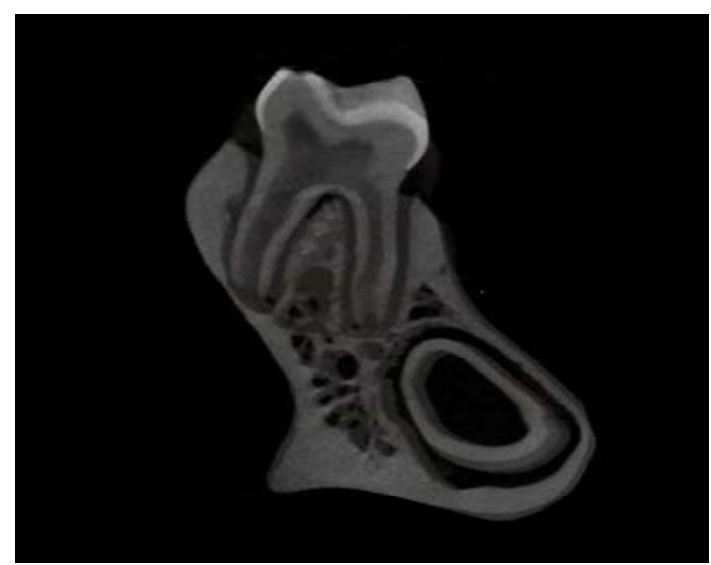

Fig. 16. The left mandible was imaged by micro-CT

\subsubsection{Microtomography of the DM mandible}

The quantification of micro-CT trabecular bone changes (mean $\pm \mathrm{SD}$ ) is shown for the DM and the control groups in (Table 4). All trabecular parameters in both alveolar bone and buccal surface of jaw bone showed significant changes. Compared with the control group, bone volume fraction (BV/TV) was significantly decreased only in the alveolar bone; however, trabecular thickness (Tb.Th) and trabecular numbers (Tb.N) were significantly decreased both in alveolar and buccal surface of jaw bone, in the DM group. Correspondingly, significantly higher trabecular separation (Tb.Sp) and trabecular space (Tb.S) were revealed both in alveolar and buccal surface of jaw bone for the DM group when compared with that of the control group. Also, the bone surface / bone volume (BS/BV) was significantly increased only in alveolar bone $(p<0.05)$. These findings indicate deterioration of the bone quality in the DM group. These results agree with other research work suggesting that the glycaemic levels play an important role in modulating the trabecular architecture especially in mandibular bone (Thrailkill et al., 2005).

The DM condition resulted in alteration of the trabecular distance and thickness as compared to the control group indicating profound impact on the histological integrity of the bone. The reduction in trabecular bone volume accompanied by the expansion of the bone marrow space is in agreement with another investigation (Duarte et al., 2005). In this context, these results may describe a state of osteopenia in experimental diabetic rats, which might be the result of an imbalance between bone formation and resorption 


\begin{tabular}{ccccc}
\hline & \multicolumn{2}{c}{ Alveolar Bone } & Buccal Surface Of The Jaw Bone \\
& DM & Control & DM & Control \\
& & & & \\
& & & & \\
& & $63.93 \pm 15.3$ & $87.8 \pm 5.6$ & $70.0 \pm 15.5$ \\
Bone Surface/Bone Volume $(1 / \mathrm{mm})$ & $36.8 \pm 9.5 *$ & $46.2 \pm 10.2$ & $37.3 \pm 4.2$ & $55.2 \pm 16.4$ \\
Bone Volume/Tissue Volume $(\%)$ & $22.1 \pm 11.6 *$ & $34.3 \pm 4.5$ & $21.5 \pm 2.9 *$ & $26.1 \pm 2.1$ \\
Trabecular Thickness $(\mu \mathrm{m})$ & $23.2 \pm 2.1 *$ & $14.4 \pm 2.6$ & $15.2 \pm 1.7 *$ & $18.9 \pm 0.7$ \\
Trabecular Number $(1 / \mathrm{mm})$ & $10.8 \pm 1.2 *$ & $25.5 \pm 2.4$ & $38.1 \pm 9.1 *$ & $25.9 \pm 2.4$ \\
Trabecular Separation $(\mu \mathrm{m})$ & $37.5 \pm 1.0 *$ & $71.2 \pm 11.5$ & $67.7 \pm 7.9 *$ & $53.1 \pm 2.0$ \\
Trabecular Space $(\mu \mathrm{m})$ & $87.6 \pm 4.3 *$ & & & \\
\hline
\end{tabular}

${ }^{*} p<0.05$ as compared to control values

Table 8. Microarchitectural properties in the mandible as measured by micro-CT

\subsection{Histological analysis}

\subsubsection{Procedure for preparing mandibles for histological analysis}

- Mandibles for all groups were decalcified in 10\% EDTA solution pH 7.4 for 5 weeks at $4^{\circ} \mathrm{C}$ (Yokoyama et al., 2009).

- Specimens are then dehydrated in an ascending ethanol series and embedded in paraffin (Figs. 9, 10, 11).

- Serial horizontal sections ( $5 \mu \mathrm{m}$ thick parallel to the occlusal plane) are prepared using a microtome (Leica RM 2155, Nussloch, Germany) (Figs. 12, 13)

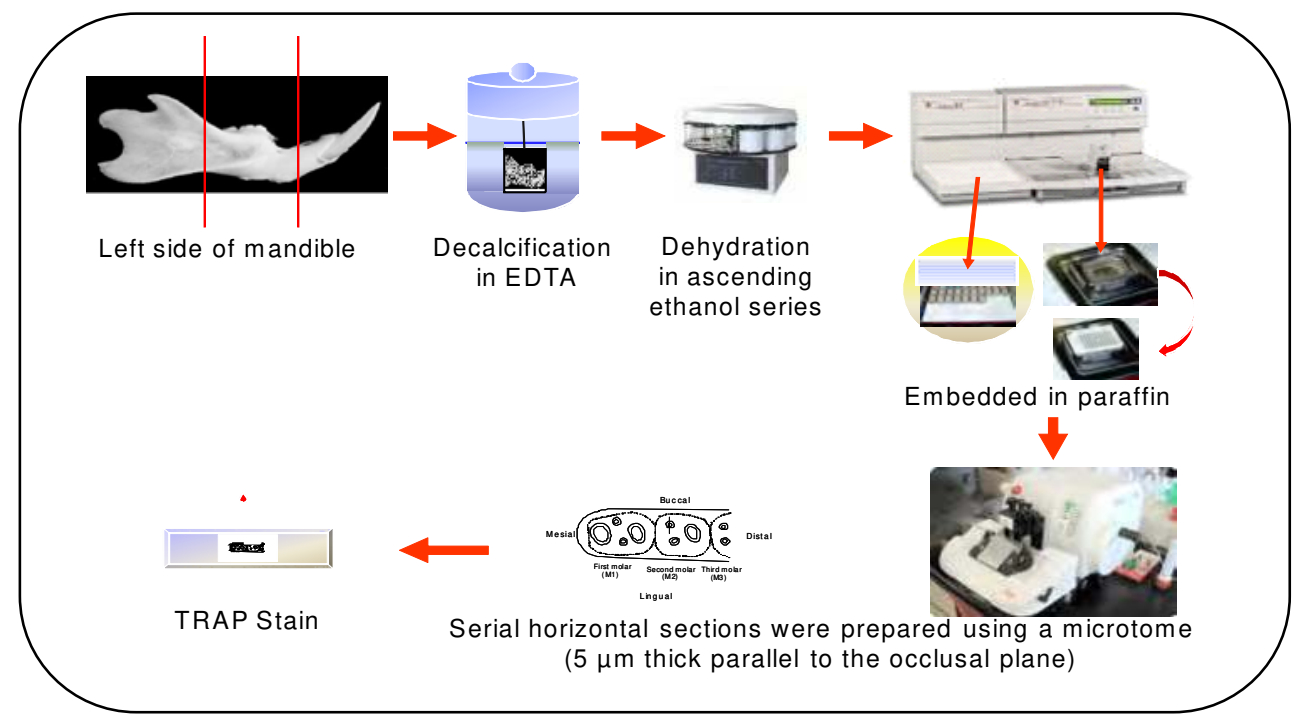

Fig. 17. Experimental procedure for histological section preparation 


\subsubsection{TRAP staining}

Histological sections are incubated for $30-60 \mathrm{~min}$ at $37^{\circ} \mathrm{C}$ in a mixture of $0.8 \%$ naphthol AS-BI phosphate (Sigma, St Louis, MO, USA), 0.7\% fast red violet salt (Sigma, St Louis, MO, USA) and $50 \mathrm{mM}$ sodium tartate diluted in $0.2 \mathrm{M}$ sodium acetate buffer $(\mathrm{pH} 5.4)$ (Tsuchiya and Kurihara, 1995). Sections were examined under a light microscope. For the histomorphometric assessment of resorption, the number of tartrate-resistant acid phosphatase-positive multinucleated cells (osteoclasts) on the distal surface of the alveolar bone adjacent to the mesio-buccal root of the second molar were counted in each $540 \mu \mathrm{m} \times 120$ $\mu \mathrm{m}$ area in five consecutive sections, at the middle third of the root selected at least $25 \mu \mathrm{m}$ apart from each specimen $(n=5)$ of each group (Misawa et al., 2007; Mishima et al., 2002).

\subsubsection{Histological analysis}

Bone-resorption activity was assessed by counting the number of tartrate-resistant acid phosphatase-positive multinucleate cells (osteoclasts) on the distal surface of the alveolar bone adjacent to the mesio-buccal root of the second molar (Fig. 18A-D). Statistical analysis
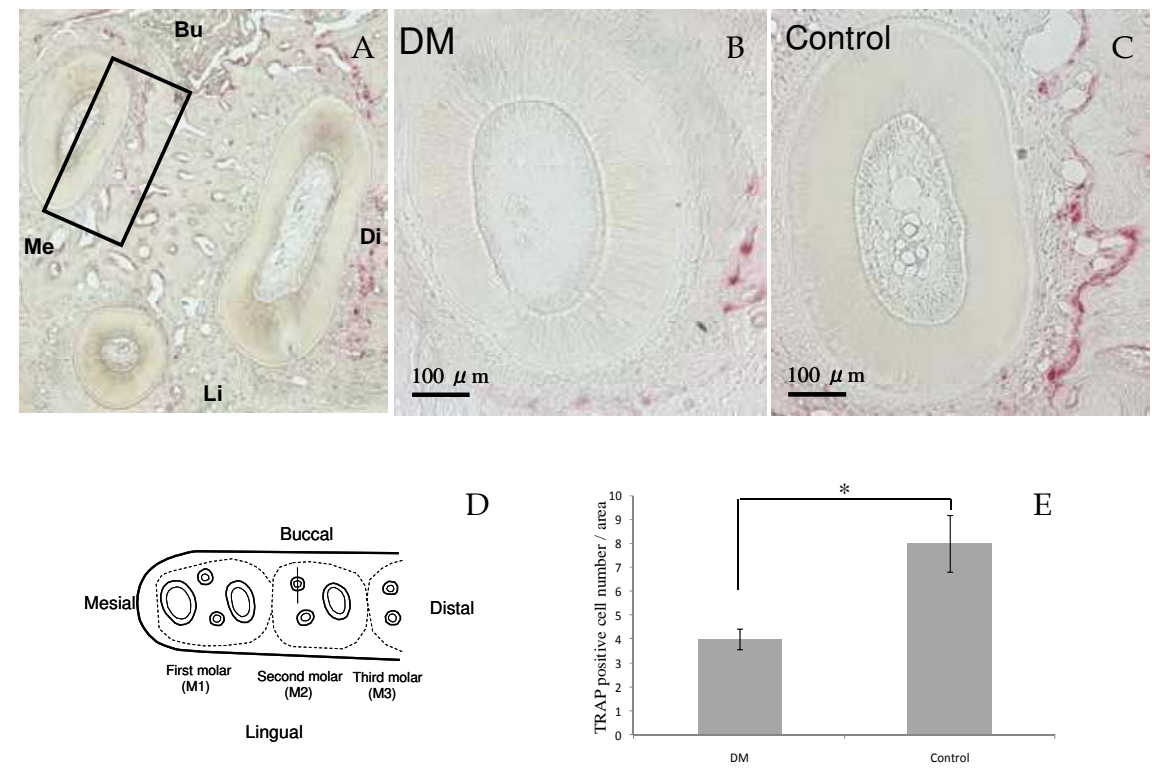

Fig. 18. Osteoclast counts in a horizontal section of the mandibular second molar region stained with Tartarate-resistant acid phosphatase (TRAP). (A) Low magnification photograph of the three roots of the second molar stained with TRAP stain. The black rectangle (540 X $120 \mu \mathrm{m})$ indicates the area on the distal surface of the alveolar bone adjacent to the middle third of the mesio-buccal root of the second molar in which the osteoclast cells were counted. Bu, buccal; $\mathrm{Li}$, lingual; Me, mesial; Di, distal. (B) The mesio-buccal root of the control rat (original magnification 100X). (C) The mesio-buccal root of the DM rat (original magnification 100X). (D) A schematic drawing showing the observation area on the distal surface of the alveolar bone adjacent to the mesio-buccal root of the second molar in which the osteoclast cells were counted. (E) The number of TRAP-positive cells on the distal surface of the mesio-buccal root of the mandibular second molar. Values are mean \pm SD. *: $(p<0.05)$, bars $=100 \mu \mathrm{m}$. 
demonstrated a significantly higher number of osteoclast cells in the control group when compared with the DM group $(p<0.05)$ (Fig. 18). Results revealed that the number of osteoclasts was significantly lower in the DM rats than in the controls, in line with previous studies on DM rats' mandible (Mishima et al., 2002) and long bones (Glajchen et al., 1988; Shires et al., 1981). These results confirm that the decreased rate of bone turnover may be associated with the DM condition.

\section{Suggested mechanisms for the effect of diabetic condition on craniofacial complex}

Growth of the craniofacial complex is controlled by genetic and environmental factors (Giglio and Lama, 2001; Yonemitsu et al., 2007). Regulatory mechanisms responsible for normal morphogenesis of the face and head involve hormones, nutrients, mechanical forces, and various local growth factors. The poor growth and alterations in bone metabolism have been associated with T1DM in both humans and experimental animals (Giglio and Lama, 2001). Because human studies can be limited by small sample sizes, cross-sectional designs, uncontrolled variables, and often retrospective nature, animal models have been used to yield more rigorous analyses (Singleton et al., 2006). In our studies we observed the rat growth from the age of 3 weeks old till 7 weeks old. This time period is corresponding to early growth stage in human according to previous craniofacial growth studies (Losken et al., 1994; Siegel and Mooney, 1990). Consequently, in the current study STZ-DM model was used to investigate the effect of T1DM on craniofacial growth.

The studied STZ-DM rats showed significantly reduced growth in most of the craniofacial skeletal units but no significant differences were observed between controls and DM group as regards the remaining craniofacial skeletal units (Sphenoid bone length, posterior neurocranium height, anterior corpus length, bigonial width and palatal width). Craniofacial growth as a whole was also significantly lower in DM group compared to controls in all three dimensions. Previous study investigated the DM effect exclusively on the growth of the mandible and suggested that the diabetic condition had a differential effect on the osseous components and / or its associated non-skeletal tissues. They found that the disharmonious growth of the mandible was due to DM condition and might not be associated with diabetic condition complications such as renal failure, anemia, body weight change or alteration in the food intake qualities (Giglio and Lama, 2001). Thus we hypothesize that the deficiency in the craniofacial growth in our experiment might be attributed to the diabetic condition in the DM group as it was reported that specific alterations in bone metabolism are associated with DM. Moreover, several pathogenic possibilities have been proposed, such as insulinopenia, bone microangiopathy, impaired regulation of mineral metabolism, alterations in local factors that regulate bone remodeling, and even an intrinsic disorder associated with T1DM (Duarte et al., 2005; Ward et al., 2001). The aforementioned insulin hormone deficiency that is associated with T1DM cases may have direct effect on bone metabolism. It was mentioned in literature that normal insulin hormone level exerts direct anabolic effects on bone cells (Duarte et al., 2005). Multiple osteoblast-like cell lines express insulin receptors on the cell surface and have a high capacity for insulin binding (Pun et al., 1989). Moreover, osteoclasts exhibit reduced bone resorption in response to insulin stimulation (Thomas et al., 1998). These findings support the idea that the actions of insulin in bone could be mediated directly via stimulation of osteoblasts in combination with inhibition of osteoclasts, (Thomas et al., 1998; Thrailkill et al., 
2005) and this mechanism of action may explain the retardation of craniofacial growth in STZ-DM.

Diabetes has a deleterious effect on osseous turnover due to decreased osteoblast and osteoclast activities and numbers and, a lower percentage of osteoid surface and osteocalcin synthesis, as well as increased time for mineralization of osteoid (Duarte et al., 2005). It was reported that the influence of diabetes on discrete stages of matrix-induced endochondral bone formation could have profound effects on the biomechanical behavior of bone. Also, chondrogenesis and calcification of bone were reduced by $50 \%$ in diabetic animals (Reddy et al., 2001). This was evident in the current study results that showed a significant decrease in the craniofacial linear measurements of the DM group.

In addition to this, insulin may exert synergistic effects with other anabolic agents in bone, such as parathyroid hormone (PTH) (Thomas et al., 1998; Thrailkill et al., 2005). An animal model of T1DM has frequently demonstrated alteration in bone turnover, retarded growth, increased concentration of PTH, and reduced concentration of 1,25-dihydroxivitamin D (Duarte et al., 2005; Tsuchida et al., 2000). The effects of PTH on the bones are complex; it stimulates resorption or bone formation depending on the concentration used, the duration of the exhibition, and the administration method (Duarte et al., 2005; Toromanoff et al., 1997; Tsuchida et al., 2000). Also, 1,25-dihydroxivitamin D, like PTH, belongs to the most important group of bone regulatory hormones. It regulates osteoclastic differentiation from hematopoietic mononuclear cells, and osteoblastic functions and activity (Collins et al., 1998; Duarte et al., 2005).

Moreover, Insulin may indirectly regulate the enhancement of growth hormone serum concentration by direct regulation of the hepatic growth hormone receptor, this results in abnormalities in the insulin growth factor-1 in T1DM (Chiarelli et al., 2004) which consequently may have lead to the retarded growth in uncontrolled DM in the current study.

In the present study most of the periosteal surfaces in the mandibular regions of the control group showed significantly higher values recorded for the mineral apposition rate and the bone formation rate when compared to the DM group. These results agree with previous studies that recorded diminished lamellar bone formation in DM rats' femur and may suggest an association between the DM condition and the decreased number and function of osteoblasts (Follak et al., 2004; Shyng et al., 2001). The alveolar crest region was the only region that did not show a significant difference in the mineral apposition rate and the bone formation rate parameters among the two groups; this may be attributed to the unique nature of this region exhibiting a highly intensive bone remodeling process especially during the teeth eruption that decreases toward the base of the socket (Gerlach et al., 2002).

Micro CT analysis showed a significant decrease of bone volume fraction, trabecular thickness, and trabecular number. Also, it showed a significant increase of the trabecular separation and the trabecular space in the DM group when compared with the control group. This finding indicates deterioration of the bone quality in the DM group. These results agree with other research work suggesting that the glycaemic levels play an important role in modulating the trabecular architecture especially in mandibular bone (Thrailkill et al., 2005). In this context, these results may describe a state of osteopenia in experimental diabetic rats, which might be the result of an imbalance between bone formation and resorption. 
A histometric evaluation of bone resorption was performed by counting the number of osteoclast cells on the distal surface of the alveolar bone adjacent to the mesio-buccal root of the second molar. These evaluations revealed that the number of osteoclasts was significantly lower in the DM rats than in the controls, in line with previous studies on DM rats' mandible (Mishima et al., 2002) and long bones (Glajchen et al., 1988; Shires et al., 1981). These studies confirm that the decreased rate of bone turnover may be associated with the DM condition.

This deteriorating effect on mandibular bone structure and dynamic bone formation might be be attributed to several pathogenic possibilities, such as insulinopenia, bone microangiopathy, impaired regulation of mineral metabolism, alterations in local factors that regulate bone remodeling, and even an intrinsic disorder associated with DM (Abbassy et al., 2008; Duarte et al., 2005). However, the detrimental effects observed may not be associated with the significant loss of rats' weights observed in the diabetic group starting from day 14 because previous research (Abbassy et al., 2008; Giglio and Lama, 2001; Shires et al., 1981; Thrailkill et al., 2005) showed that the mandibular growth was not affected in normal rats supplied with restricted diet and having same pattern of weight loss resembling weight loss pattern observed in DM rats.

\section{Conclusions}

It is obvious that the T1DM condition significantly affects craniofacial growth, bone formation mechanism and the quality of the bone formed which may alter many aspects of planning and treatment of orthodontic patients affected by this globally increasing hormonal disturbance.

There should be a new strategy for treating orthodontic patients suffering from metabolic disorders specially those disorders having direct and indirect effects on bone growth as the diabetic condition. The orthodontic craniofacial linear measurements were significantly decreased in the T1DM cases when compared to normal cases. These facts should be considered when orthodontic problems are diagnosed and treated in T1DM, because this may alter the orthodontic treatment period and the final treatment outcome. In this chapter it was suggested that a better understanding of how diabetes affects bone will improve our ability to protect bone health in diabetic patients. Also, it was recommended to conduct further studies in order to elucidate the exact mechanism by which diabetes produces alterations in most of the craniofacial units.

Thus, T1DM condition had detrimental effects on the different bone regions of the mandible, that shed the light on the complexity of the craniofacial structure which is affected by many hormonal disorders suggesting further examination for the overlying soft tissues which are directly affected by any underlying boney changes. Diabetes condition had detrimental effect on bone architecture, as shown by micro-CT, and impaired the rate of the mandibular bone formation, as examined by the dynamic histomorphometric analysis. All of these results were verified on the cellular level by a histological study that showed the diminished number of osteoclasts on the alveolar wall, suggesting that the early stage of T1DM resulted in low bone turnover. These results may suggest that more care is needed during the consideration of the force needed for treatment of orthodontic patients affected by T1DM, also, the retention period and rate of success in these patients may be affected.

These comprehensive studies done on bone and craniofacial growth suggest that planning the treatment in craniofacial region for patients affected with hormonal disorders is a more 
complex procedure when compared to the treatment of normal patients, moreover it is suggested that it is of prime importance to keep close attention to the general systemic condition of these patients and administer the proper hormonal therapy for these patients when needed to avoid any detrimental effects on bone resulting from any hormonal imbalance.

Within the limitations of this in vitro study, it was concluded that:

1. T1DM reduces craniofacial growth, resulting in retardation of skeletal development.

2. DM in the rat affects the bone architecture, as shown by micro-CT, and impairs the rate of the mandibular bone formation, as examined by the dynamic histomorphometric analysis.

3. All of these results were verified on the cellular level by a histological study that showed the diminished number of osteoclasts on the alveolar wall, suggesting that the early stage of DM resulted in low bone turnover.

4. These findings should be considered when conducting any treatment in the craniofacial region in T1DM since the better understanding of how diabetes affects bone will improve our ability to protect bone health in diabetic patients.

5. Good control of diabetes mellitus should be considered before orthodontic treatment by a long time inorder to obtain the best outcome.

\section{References}

Abbassy MA, Watari I, Soma K (2008). Effect of experimental diabetes on craniofacial growth in rats. Archives of Oral Biology, Vol.53, No.9, (September 2008), pp. 819-825

Abbassy MA, Watari I, Soma K (2010). The effect of diabetes mellitus on rat mandibular bone formation and microarchitecture European Journal of Oral Sciences, Vol.118, No.4, (August 2010), pp. 364-369

Abdus Salam M, Matsumoto N, Matin K, Tsuha Y, Nakao R, Hanada N, Senpuku H (2004). Establishment of an animal model using recombinant NOD.B10.D2 mice to study initial adhesion of oral streptococci. Clinical and Diagnostic Laboratory Immunology, Vol.11, No.2, (March 2004), pp. 379-386

Alkan A, Erdem E, Gunhan O, Karasu C (2002). Histomorphometric evaluation of the effect of doxycycline on the healing of bone defects in experimental diabetes mellitus: a pilot study. Journal of Oral and Maxillofacial Surgery, Vol. 60, No.8, (August 2002), pp.898-904

Bensch L, Braem M, Van Acker K, Willems G (2003). Orthodontic treatment considerations in patients with diabetes mellitus. American Journal of Orthodontics and Dentofacial Orthopedics, Vol.123, No.1, (January 2003), pp. 74-78

Chew FS (1991). Radiologic manifestations in the musculoskeletal system of miscellaneous endocrine disorders. Radiologic Clinics of North America, Vol.29, No.1, (January1991), pp. 135-147, ISSN 0033-8389

Chiarelli F, Giannini C, Mohn A (2004). Growth, growth factors and diabetes. European Journal of Endocrinology, Vol.151, Suppl 3, (November 2004), pp.U109-117

Chidiac JJ, Shofer FS, Al-Kutoub A, Laster LL, Ghafari J (2002). Comparison of CT scanograms and cephalometric radiographs in craniofacial imaging. Orthodontics and Craniofacial Research, Vol.5, No.2, (May 2002), pp.104-113

Collins D, Jasani C, Fogelman I, Swaminathan R (1998). Vitamin D and bone mineral density. Osteoporosis International, Vol.8, No.2, (March 1998), pp. 110-114, ISSN 0937-941X 
Duarte VM, Ramos AM, Rezende LA, Macedo UB, Brandao-Neto J, Almeida MG, Rezende AA (2005). Osteopenia: a bone disorder associated with diabetes mellitus. Journal of Bone and Mineral Metabolism, Vol.23, No.1, (January 2005), pp. 58-68

Eastell R, Lambert H (2002). Diet and healthy bones. Calcified Tissue International, Vol.70, No.5, (May 2002), pp. 400-404

Engstrom C, Jennings J, Lundy M, Baylink DJ (1988). Effect of bone matrix-derived growth factors on skull and tibia in the growing rat. Journal of Oral Pathology, Vol.17, No.7, (August 1988), pp. 334-340, ISSN 0300-9777

Follak N, Kloting I, Wolf E, Merk H (2004). Histomorphometric evaluation of the influence of the diabetic metabolic state on bone defect healing depending on the defect size in spontaneously diabetic BB/OK rats. Bone, Vol.35, No.1, (July 2004), pp. 144-152

Gerlach RF, Toledo DB, Fonseca RB, Novaes PD, Line SR, Merzel J (2002). Alveolar bone remodelling pattern of the rat incisor under different functional conditions as shown by minocycline administration. Archives of Oral Biology, Vol.47, No.3, (March 2002), pp. 203-209

Giglio MJ, Lama MA (2001). Effect of experimental diabetes on mandible growth in rats. European Journal of Oral Sciences, Vol.109, No.3, (June 2001), pp. 193-197

Glajchen N, Epstein S, Ismail F, Thomas S, Fallon M, Chakrabarti S (1988). Bone mineral metabolism in experimental diabetes mellitus: osteocalcin as a measure of bone remodeling. Endocrinology, Vol.123, No.1, (July 1988), pp. 290-295, ISSN 0013-7227

Hough S, Avioli LV, Bergfeld MA, Fallon MD, Slatopolsky E, Teitelbaum SL (1981). Correction of abnormal bone and mineral metabolism in chronic streptozotocininduced diabetes mellitus in the rat by insulin therapy. Endocrinology, Vol. 108, No.6, (June 1981), pp. 2228-2234, ISSN 0013-7227

Keshawarz NM, Recker RR (1986). The label escape error: comparison of measured and theoretical fraction of total bone-trabecular surface covered by single label in normals and patients with osteoporosis. Bone, Vol. 7, No.2, (February 1986), pp. 83-87

Kiliaridis S EC, Thilander B. (1985). The relationship between masticatory function and craniofacial morphology. I. A cephalometric longitudinal analysis in the growing rat fed a soft diet. European Journal of Orthodontics, Vol.7, pp. 273-283

Kitabchi AE UG, Murphy MB, Barrett EJ, Kreisberg, RA, Malone JI, et al. (2001). Management of hyper-glycemic crises in patients with diabetes. Diabetes Care, Vol.24, pp. 131-153

Kumar P, Clark, M. (2009). Kumar and Clark's Clinical Medicine (7th edition), Elsevier, ISBN 10: 0-7020-2993-9, ISBN 13: 978-0-7020-2993-6, London, UK

Laib A, Ruegsegger P (1999). Calibration of trabecular bone structure measurements of in vivo three-dimensional peripheral quantitative computed tomography with 28-micromresolution microcomputed tomography. Bone, Vol.24, No.1, (January 1999), pp. 35-39

Losken A, Mooney MP, Siegel MI (1994). Comparative cephalometric study of nasal cavity growth patterns in seven animal models. Cleft Palate Craniofacial Journal, Vol.31, No.1, (January 1994), pp.17-23

Lu H, Kraut D, Gerstenfeld LC, Graves DT (2003). Diabetes interferes with the bone formation by affecting the expression of transcription factors that regulate osteoblast differentiation. Endocrinology, Vol.144, No.1, (January 2003), pp.346-352, ISSN 0013-7227

Matin K, Salam MA, Akhter J, Hanada N, Senpuku H (2002). Role of stromal-cell derived factor- 1 in the development of autoimmune diseases in non-obese diabetic mice. Immunology, Vol.107, No.2, (October 2002), pp.222-232, ISSN 0019-2805 
McCracken MS, Aponte-Wesson R, Chavali R, Lemons JE (2006). Bone associated with implants in diabetic and insulin-treated rats. Clinical Oral Implants Research, Vol.17, No.5, (October 2006), pp. 495-500

Misawa Y, Kageyama T, Moriyama K, Kurihara S, Yagasaki H, Deguchi T, Ozawa H, Sahara $\mathrm{N}$ (2007). Effect of age on alveolar bone turnover adjacent to maxillary molar roots in male rats: A histomorphometric study. Archives of Oral Biology, Vol.52, No.1, (January 2007), pp. 44-50

Mishima N, Sahara N, Shirakawa M, Ozawa H (2002). Effect of streptozotocin-induced diabetes mellitus on alveolar bone deposition in the rat. Archives of Oral Biology, Vol.47, No.12, (December 2002), pp. 843-849, ISSN 0003-9969

Nakano H, Maki K, Shibasaki Y, Miller AJ (2004). Three-dimensional changes in the condyle during development of an asymmetrical mandible in a rat: a microcomputed tomography study. American Journal of Orthodontics and Dentofacial Orthopedics, Vol.126, No.4, (October 2004), pp. 410-420

Parfitt AM, Drezner MK, Glorieux FH, Kanis JA, Malluche H, Meunier PJ, Ott SM, Recker RR (1987). Bone histomorphometry: standardization of nomenclature, symbols, and units. Report of the ASBMR Histomorphometry Nomenclature Committee. Journal of Bone and Mineral Research, Vol.2, No.6, (December 1987), pp. 595-610

Pun KK, Lau P, Ho PW (1989). The characterization, regulation, and function of insulin receptors on osteoblast-like clonal osteosarcoma cell line. Journal of Bone and Mineral Research, Vol.4, No.6, (December 1989), pp. 853-862

Reddy GK, Stehno-Bittel L, Hamade S, Enwemeka CS (2001). The biomechanical integrity of bone in experimental diabetes. Diabetes Research and Clinical Practice, Vol.54, No.1, pp. 1-8, ISSN 0168-8227

Salzmann JA (1966). Practice of orthodontics. American Journal of Orthodontics, Vol. 76, No.1, (July 1979), pp. 103-104

Schwartz AV (2003). Diabetes Mellitus: Does it Affect Bone? Calcified Tissue International, Vol.73, No.6, (December 2003), pp. 515-519

Sheng MH, Baylink DJ, Beamer WG, Donahue LR, Rosen CJ, Lau KH, Wergedal JE (1999). Histomorphometric studies show that bone formation and bone mineral apposition rates are greater in $\mathrm{C} 3 \mathrm{H} / \mathrm{HeJ}$ (high-density) than $\mathrm{C} 57 \mathrm{BL} / 6 \mathrm{~J}$ (low-density) mice during growth. Bone, Vol.25, No.4, (October 1999), pp. 421-429

Shimomoto Y, Chung CJ, Iwasaki-Hayashi Y, Muramoto T, Soma K (2007). Effects of occlusal stimuli on alveolar/jaw bone formation. Journal of Dental Research, Vol.86, No.1, (January 2007), pp. 47-51

Shimomoto Y IY, Chung C-R, Muramoto T, Soma K. ( 2005). Occlusal stimuli affects alveolar and jaw bone formation during the growth period. . Journal of Japanese Society of Bone Morphometry, Vol.15, No.1, pp. 29-34, ISSN 0917-4648

Shires R, Teitelbaum SL, Bergfeld MA, Fallon MD, Slatopolsky E, Avioli LV (1981). The effect of streptozotocin-induced chronic diabetes mellitus on bone and mineral homeostasis in the rat. Journal of Laboratory Clinical Medicine, Vol.97, No.2, (February 1981), pp. 231-240, ISSN 0022-2143

Shyng YC, Devlin H, Sloan P (2001). The effect of streptozotocin-induced experimental diabetes mellitus on calvarial defect healing and bone turnover in the rat. International Journal of Oral and Maxillofacial Surgery, Vol.30, No.1, (February 2001), pp. 70-74

Siegel MI, Mooney MP (1990). Appropriate animal models for craniofacial biology. Cleft Palate Journal, Vol.27, No.1, (January 1990), pp. 18-25 
Singleton DA, Buschang PH, Behrents RG, Hinton RJ (2006). Craniofacial growth in growth hormone-deficient rats after growth hormone supplementation. American Journal of Orthodontics and Dentofacial Orthopedics, Vol.130, No.1, (July 2006), pp. 69-82

Stuart A, Smith D (1992). Use of the Fluorochromes xylenol orange, calcein green, and tetracycline to document bone deposition and remodeling in healing fractures in chickens. Avian diseases, Vol.36, (July 1992), pp. 447-449

Takada H, Abe S, Tamatsu Y, Mitarashi S, Saka H, Ide Y (2006). Three-dimensional bone microstructures of the mandibular angle using micro-CT and finite element analysis: relationship between partially impacted mandibular third molars and angle fractures. Dent Traumatol, Vol.22, No.1, (February 2006), pp. 18-24

Tein MS, Breen SA, Loveday BE, Devlin H, Balment RJ, Boyd RD, Sibley CP, Garland HO (1998). Bone mineral density and composition in rat pregnancy: effects of streptozotocin-induced diabetes mellitus and insulin replacement. Experimental Physiology, Vol.83, No.2, (March 1998), pp. 165-174

Thomas DM, Udagawa N, Hards DK, Quinn JM, Moseley JM, Findlay DM, Best JD (1998). Insulin receptor expression in primary and cultured osteoclast-like cells. Bone, Vol.23, No.3, (September 1998), pp. 181-186

Thrailkill KM, Liu L, Wahl EC, Bunn RC, Perrien DS, Cockrell GE, Skinner RA, Hogue WR, Carver AA, Fowlkes JL, Aronson J, Lumpkin CK, Jr. (2005). Bone formation is impaired in a model of type 1 diabetes. Diabetes, Vol.54, No.10, (October 2005), pp. 2875-2881

Toromanoff A, Ammann P, Mosekilde L, Thomsen JS, Riond JL (1997). Parathyroid hormone increases bone formation and improves mineral balance in vitamin D-deficient female rats. Endocrinology, Vol.138, No.6, (June 1997), pp. 2449-2457, ISSN 0013-7227

Tsuchida T, Sato K, Miyakoshi N, Abe T, Kudo T, Tamura Y, Kasukawa Y, Suzuki K (2000). Histomorphometric evaluation of the recovering effect of human parathyroid hormone (1-34) on bone structure and turnover in streptozotocin-induced diabetic rats. Calcified Tissue International, Vol.66, No.3, (March 2000), pp. 229-233

Tsuchiya T MY, Kurihara S. (1995). The fluorescent simultaneous azo dye technique for demonstration of tartarate -resistant acid phosphatase (TRAP) activity in osteoclastlike multinucleate cells. Journal of Bone and Mineral Metabolism, Vol.13, pp. 71-76

Vandeberg JR, Buschang PH, Hinton RJ (2004a). Craniofacial growth in growth hormonedeficient rats. The Anatomical Record. Part A, Discoveries in Molecular, Cellular and Evolutionary Biology, Vol.278, No.2, (June 2004), pp. 561-570, ISSN 1552-4884

VandeBerg JR, Buschang PH, Hinton RJ (2004b). Absolute and relative growth of the rat craniofacial skeleton. Archives of Oral Biology, Vol.49, No.6, (June 2004), pp. 477-484, ISSN 0003-9969Ward DT, Yau SK, Mee AP, Mawer EB, Miller CA, Garland HO, Riccardi D (2001). Functional, molecular, and biochemical characterization of streptozotocin-induced diabetes. Journal of the American Society of Nephrology, Vol.12, No.4, pp. 779-790, ISSN 1046-6673

Yokoyama M, Atsumi T, Tsuchiya M, Koyama S, Sasaki K (2009). Dynamic changes in bone metabolism in the rat temporomandibular joint after molar extraction using bone scintigraphy. Europen Journal of Oral Sciences, Vol.117, No. 4, (August 2009), pp. 374379, ISSN 1600-0722

Yonemitsu I, Muramoto T, Soma K (2007). The influence of masseter activity on rat mandibular growth. Archives of Oral Biology, Vol.52, No.5, (May 2007), pp. 487-493, ISSN 0003-9969

Zhang X, Fei Y, Zhang M, Wei D, Li M, Ding W, Yang J (2008). Reversal of osteoporotic changes of mineral composition in femurs of diabetic rats by insulin. Biological Trace Element Research, Vol.121, No.3, (March 2008), pp. 233-242 


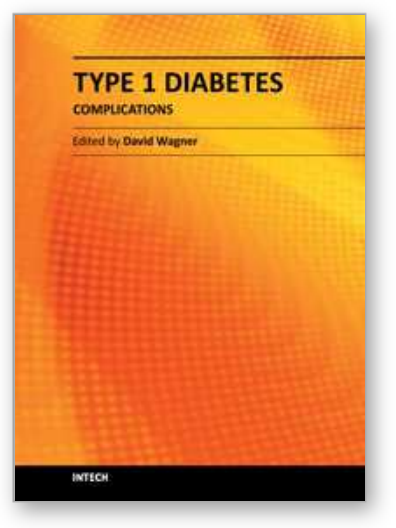

\author{
Type 1 Diabetes Complications \\ Edited by Prof. David Wagner
}

ISBN 978-953-307-788-8

Hard cover, 482 pages

Publisher InTech

Published online 25, November, 2011

Published in print edition November, 2011

This book is a compilation of reviews about the complication of Type 1 Diabetes. T1D is a classic autoimmune disease. Genetic factors are clearly determinant but cannot explain the rapid, even overwhelming expanse of this disease. Understanding etiology and pathogenesis of this disease is essential. The complications associated with T1D cover a range of clinical obstacles. A number of experts in the field have covered a range of topics for consideration that are applicable to researcher and clinician alike. This book provides apt descriptions of cutting edge technologies and applications in the ever going search for treatments and cure for diabetes.

\title{
How to reference
}

In order to correctly reference this scholarly work, feel free to copy and paste the following:

Mona Abbassy, Ippei Watari and Takashi Ono (2011). The Effect of Type 1 Diabetes Mellitus on the Craniofacial Complex, Type 1 Diabetes Complications, Prof. David Wagner (Ed.), ISBN: 978-953-307-788-8, InTech, Available from: http://www.intechopen.com/books/type-1-diabetes-complications/the-effect-of-type-1diabetes-mellitus-on-the-craniofacial-complex

\section{INTECH}

open science | open minds

\section{InTech Europe}

University Campus STeP Ri

Slavka Krautzeka 83/A

51000 Rijeka, Croatia

Phone: +385 (51) 770447

Fax: +385 (51) 686166

www.intechopen.com

\section{InTech China}

Unit 405, Office Block, Hotel Equatorial Shanghai

No.65, Yan An Road (West), Shanghai, 200040, China

中国上海市延安西路65号上海国际贵都大饭店办公楼 405 单元

Phone: +86-21-62489820

Fax: $+86-21-62489821$ 
(C) 2011 The Author(s). Licensee IntechOpen. This is an open access article distributed under the terms of the Creative Commons Attribution 3.0 License, which permits unrestricted use, distribution, and reproduction in any medium, provided the original work is properly cited. 